\title{
De les competències als projectes: una proposta des de les àrees curriculars
}

\author{
Josep Maria Pons i Altés. Didàctica de les Ciències Socials, Universitat Rovira i Virgili \\ Albert Macaya Ruiz. Didàctica de l'Expressió Plàstica, Universitat Rovira i Virgili \\ Luisa Girondo Pérez. Didàctica de les Matemàtiques, Universitat Rovira i Virgili \\ Antoni Gavaldà Torrents. Didàctica de les Ciències Socials, Universitat Rovira i Virgili \\ Carmen Conde Delgado de Molina. Psicologia Evolutiva i de l'Educació, Universitat Rovira \\ i Virgili
}

\section{Resum}

La noció de competència ha comportat alguns canvis significatius en la forma com ens plantegem l'acció didàctica a les aules. Lèmfasi en l'aplicabilitat dels aprenentatges i la relació amb els contextos de l'alumnat van paral.lels a l'interès per les propostes interdisciplinàries. En aquest article, hi plantegem i valorem una experiència de treball interdisciplinari en el context de la formació inicial de mestres. Tant la reflexió prèvia com la concreció del projecte han estat el resultat d'un treball conjunt de professors de diverses àrees de didàctiques especifiques i de psicologia de l'educació.

Paraules clau: treball per projectes, didàctiques específiques, competències.

\section{Abstract}

The notion of competence has led to significant changes in the approach to teaching in the classroom. The emphasis on the applicability of learning and its relation to the students' contexts runs parallel to the interest in interdisciplinary proposals. In this proposal, we discuss and evaluate an experience of interdisciplinary work in the context of basic teacher training. Both the planning and the implementation of the project were the result of teachers from different teaching areas and from educational psychology working as a team.

Key words: project work, specific teaching areas, competencies.

\section{Nous contextos per a ensenyar i aprendre}

La complexitat de la societat actual porta a exigir als currículums que els alumnes desenvolupin un aprenentatge eficaç, aplicable a situacions diverses de la vida. És un aprenentatge que implica que l'alumne ha de construir el seu propi coneixement de manera activa. D'un temps ençà, la noció de competència s'ha situat al centre del debat educatiu. El terme competència ha estat objecte d'interpretacions diverses $i$, en termes curriculars, ha conegut concrecions diferenciades segons l'indret. Un currículum realment centrat en el desenvolupament de les competències hauria de posar l'accent en l'aplicabilitat dels aprenentatges, donar peu a un treball interdisciplinari que estigui vinculat a l'experiència propera i que faciliti el marc per practicar processos intel-lectuals complexos - una qüestió que ja vam tractar en un article anterior (GAVALDÀ, GIrondo, Macaya, Pons i Conde, 2010).

Cada cop som més conscients que el coneixement no és abstracte, sinó que la capacitat d’aplicar-lo en contextos propers dóna també sentit a l'aprenentatge escolar. Això no vol dir que els continguts curriculars deixin de tenir sentit. Tal com ens recorda Escamilla (2008), funcionalitat i saber estan inevitablement vinculats:

Las competencias son capacidades relacionadas, de manera prioritaria, con el saber hacer; la consideración de funcionalidad y practicidad de la competencia no la reduce a un carácter meramente mecá- 
nico. El saber hacer posee, también, una dimensión de carácter teórico-comprensivo.

No es pot menystenir el perill d'entendre la competència com una cosa desvinculada dels sabers específics. Certament, la idea de ser competent apunta cap a allò interdisciplinari; però sovint, en làmbit escolar, ens movem en contextos disciplinaris específics. Com afirma del Pozo (2010), no tan sols confrontem els nostres alumnes amb continguts específics, sinó també amb modes de raonament específics. No s'ensenya de la mateixa manera un contingut de matemàtiques que un problema de llenguatge, o un fragment de música. De la mateixa manera que no raonem igual el temps històric, els nombres enters o les arts visuals.

L'especificitat de camp marca la tasca que fem; de manera que, per arribar a allò interdisciplinari, transversal, no ho fem ex nihilo, en abstracte: ho fem a través d'aprenentatges específics.

Aquestes consideracions són pertinents a l'hora de traduir la teoria en acció didàctica. Ens referim a les metodologies diverses d'aula, sorgides els darrers anys, encaminades a assolir el paper actiu de l'alumne en situacions properes a la vida quotidiana $i$ als seus interessos. Es valora també que l'ensenyament tradicional està excessivament compartimentat (KINCHELOE, 2001) i que, tal vegada, presentant situacions més reals que aportin ja la complexitat social, l'alumne aprendrà a enfrontar-s'hi i farà servir, d'una manera significativa, les eines de les diferents disciplines curriculars.

Algunes de les diferents metodologies que han anat apareixent lligades, més o menys, al concepte d'interdisciplinarietat són el treball per resolució de problemes reals i el treball per projectes. Cal considerar, a més, en qualsevol situació d'aprenentatge, la motivació de l'alumne, ja que l'aprenentatge és un acte individual i íntim: ningú no aprèn, si no vol. Ja des de clàssics moderns com ara Dewey o Decroly, s'ha parlat de la necessitat d'introduir centres d'interès que englobin la major part del treball escolar (ARANDA Hernando, 2003, 186-196).

Ara ha agafat certa força, al nostre país, la idea del treball per projectes. El treball per projectes, a la vista de diferents referències bibliogràfiques, permet diverses interpretacions. La primera interpretació consisteix que els docents trien un tema proper al medi escolar i el proposen als alumnes; aquesta temàtica - per exemple el riu que és a prop del centre- es passa a estudiar com un camp en el qual es poden aplicar nocions, representacions i procediments específics treballats en disciplines diferents. La globalitat necessària per afrontar aquesta situació afegeix, a més, un plus de qualitat als aprenentatges, ja que obliga a ajustar els models teòrics, a veure la interdependència dels fenòmens, etc. Aquesta interpretació del projecte és la que es dóna, per exemple, en la realització del denominat crèdit de síntesi que fan els alumnes en finalitzar els diferents nivells d'educació secundària. I valorem que és també la interpretació del currículum de primària, quan demana que els alumnes facin un petit projecte al final de cada cicle.

Una interpretació una mica diferent del treball per projectes i que prima l'interès dels alumnes és la que exposem a continuació.

El projecte de treball es genera, a la classe, com a conseqüència d'un interès manifestat $o$ incitat en els alumnes i pactat per ells, si apareixen diferents interessos. En principi, es vol saber alguna cosa d'una determinada temàtica - no necessàriament lligada a diverses àrees curriculars. El paper del professor és d'organitzador d'aquest treball d'indagació, i haurà de tenir l'habilitat de suggerir camins i eines curriculars, per tal que els alumnes avancin i construeixin les eines pertinents (HERnÁNDEZ i VENTURA, 1994).

El treball es farà en grup, i cada alumne hi contribuirà, en funció de les seves possibilitats, animat pel mestre que coordina el procés. Una de les premisses és aconseguir la construcció social de l'aprenentatge. El que succeeix al llarg del procés pot propiciar canvis importants en la manera com hem entès habitualment el fet d'ensenyar i aprendre. Com remarquen Anguita, Hernández i Ventura (2010), ens condueix a:

Replantear la relación entre información, conocimiento y saber; revisar la desvinculación entre el sujeto que aprende y el aprendizaje; y quebrar la distancia entre el dentro y el fuera de la escuela, entre lo establecido y lo emergente. 
Amb la gran disponibilitat d'informació a què tenim accés avui en dia, el primer requisit és saber cercar-la, triar-la i organitzar-la.

Com és sabut, les fases en què s'organitza el treball per projectes inclouen una primera recollida de possibles temes, un debat i el consens (o votació) entre els participants, un procés de cerca d'informació, una síntesi i una recapitulació final del que hem après.

Seguint Domínguez (2007), una descripció de les fases del treball, referides al rol del professor, passaria per:

1. Elegir el tema i revisar-ne la connexió amb altres temes o continguts curriculars treballats prèviament.

2. Analitzar la connexió del tema amb el projecte curricular del centre.

3. Fer una primera previsió de continguts i activitats.

4. Estudiar i preparar el tema, afinant la selecció d'informació amb una bona definició de l'objecte d'estudi.

5. Crear un clima de participació i interès, propiciar el treball cooperatiu.

6. Mantenir una actitud avaluadora, tant al principi del projecte (què sabem sobre el tema?) com durant el desenvolupament (què estem aprenent?, com estem conduint el treball? ) i al final (què hem après?)

7. Recapitular el procés, per tal de dissenyar pautes per a processos posteriors.

Basant-nos en aquests referents, ressenyem a continuació una experiència que hem dut a terme en el context de la formació de mestres d'educació primària.

\section{Un exemple de projecte}

Lactivitat que explicarem a continuació es va portar a la pràctica en l'assignatura Ciències Socials i la seva Didàctica II, de tercer de la Diplomatura de Mestre en Educació Primària (curs 2010-2011).

Vam començar tot posant en comú les vivències prèvies de projectes que els nostres estudiants havien vist en funcionament a les escoles en els mesos que havien fet pràctiques. I és digne de remarcar-ne la gran diversitat: des de projec- tes que havien esdevingut una mena d'activitat extraescolar amb objectius didàctics poc clars $i$ amb activitats rutinàries, fins a escoles que els situaven al centre de tota la seva acció docent. En conseqüència, alguns dels estudiants venien amb prejudicis negatius, mentre que d'altres en tenien una valoració molt positiva. ${ }^{1}$

Tot seguit, ens va sembla convenient exposar un exemple preparat prèviament pels signants d'aquest article, un possible projecte pensat per a cicle superior de primària. Lobjectiu no era donar-los un model tancat que calia seguir, sinó, primer, compartir amb ells la nostra tasca prèvia i, sobretot, els dubtes i problemes que havíem tingut $i$, després, debatre el nostre esquema final.

Per tant, uns quants mesos abans ja havíem fet, pel nostre compte, una mena de simulació, a partir d'un tema que no havia sorgit de l'interès d'alumnes reals de primària, sinó del que nosaltres suposàvem que es podria arribar a treballar en una escola. El tema triat va ser la polèmica existent sobre el projecte d'autovia TarragonaMontblanc (l'A-27), que hauria d'acabar enllaçant cap a Lleida i el nord de l'Estat espanyol.

Lautovia està prevista sobre un nou traçat, a pesar que inicialment hi hagué demandes a favor de desdoblar, de Tarragona a Valls, la carretera $\mathrm{N}-240$. I aquest nou traçat projectat ha rebut crítiques des de diverses instàncies, com ara d`un sector de la pagesia (perquè malmet conreus, comporta expropiacions i desvia cursos d'aigua), de grups ecologistes (pel cost mediambiental que implica i el perill que el polígon petroquímic s'acabi eixamplant cap a l'interior) o d'alguns municipis (perquè divideix el seu terme municipal o passa massa a prop de nuclis habitats).

Vam consultar alguns dels volums del projecte dipositat a la Delegació de Tarragona del Ministeri de Foment, amb l'objectiu de fer-nos una primera idea general de les característiques de la futura autovia i conèixer els paràmetres tècnics que s'hi feien constar a cada tram: dades climatològiques, volum d'expropiacions, accessos, impacte ecològic, reconstrucció de camins, etc.

1 Un projecte realitzat efectivament en una escola, amb una observació precisa i analítica, és el que presenta Martín García (2006). 
Finalment el nostre projecte va quedar formulat amb el títol "La construcció de l'autovia Tarragona-Montblanc: avantatges i inconvenients, beneficis i costos". Vam seguir les passes de la metodologia del treball per projectes i ens vam plantejar què sabíem i què volíem saber o què ens faltava per saber. Tot seguit vam preparar una planificació final d'activitats que es pogués aplicar al cicle superior de primària i que hauria de permetre tenir una opinió fonamentada sobre la polèmica.

Amb els nostres estudiants de la diplomatura, en lloc de donar-los tot el nostre esquema com un treball tancat i definitiu, vam optar per intentar reproduir-lo a l'aula a partir de les seves pròpies aportacions.

Tal com era previsible, les idees principals que van sorgir foren ben semblants a les que nosaltres havíem pensat.

1) En preguntar-los què sabien, van aparèixer comentaris com ara:

hi haurà destrucció de conreus i expropiacions de terrenys, la nova autovia tindrà un cost ecològic i econòmic, causarà molèsties als habitants de les poblacions properes, la mobilitat en cotxe serà més ràpida $\mathrm{i}$ segura, millorarà les condicions en què circula el tràfic pesat, permetrà una evacuació més ràpida de la població en cas d'accident a la indústria petroquímica, generarà llocs de treball i beneficis per a determinats sectors productius del territori, o la decisió no ha estat presa pels ajuntaments, sinó per instàncies polítiques superiors.

2) Les idees sobre què volíem o necessitàvem saber també van ser similars a les que nosaltres havíem preparat prèviament. Sovint, una bona prova que un projecte té viabilitat és comprovar que els interessos i l'esquema final de treball acaben gravitant al voltant de preguntes similars, al marge de les persones que el facin. I, en el nostre cas, així va ser.

3) L'esquema final de la planificació del projecte, de les activitats que calia realitzar i que nosaltres havíem dibuixat, per tal de respondre les preguntes plantejades, era molt semblant al que va anar sorgint durant el debat a classe amb els nostres estudiants. L'esquema havia estat el següent:
- Com es prenen les decisions polítiques que envolten l'aprovació i construcció de la infraestructura: quins organismes hi estan implicats, en què consisteix la dinàmica de la presa de decisions polítiques, què és una expropiació (i què comporta contraposar l'interès privat i l'interès comú).

- Descripció i comprensió del territori afectat: l'orografia, el paisatge i els conreus; quantificació i distribució de la població; els principals nuclis productius i centres de distribució; el pes econòmic i demogràfic del Camp de Tarragona en el conjunt de Catalunya.

- Cost ecològic i patrimonial de la infraestructura: definició de patrimoni i nivells de protecció; estudi del cost ecològic, patrimonial i paisatgístic de l'autovia en un municipi concret.

- Aspectes econòmics: quines són les prioritats econòmiques a l'hora de construir vies de comunicació, dificultats del traçat, cost econòmic de l'autovia, comparació de la capacitat, la perillositat, la llargada i el temps de viatge entre la carretera N-240 i la futura autovia.

- Balanç final: ser capaços de conèixer els avantatges i els inconvenients del projecte de lautovia per poder opinar amb fonament.

\section{Propostes de treball per a projectes a primària des de l'aula universitària}

A continuació, els estudiants de l'assignatura es van repartir en vuit grups (entre 6 i 8 integrants a cada grup) i cadascun va haver de preparar un projecte per a sisè curs de primària. El conjunt d'activitats previstes en cada projecte havia d'ocupar entre 15 i 30 hores.

Tots els implicats érem conscients que es tractava d'una simulació i dels problemes que això comportava: no hi havia nens que proposessin el tema del projecte, sinó que cada grup s'imaginava un tema que probablement podrien triar uns alumnes de sisè de primària; la resposta a les preguntes sobre què sabien i què volien saber també depenia d'allò que intuïssin que uns nens d'1112 anys poguessin contestar. Potser encara era més important saber que el projecte no es podria aplicar amb alumnes de primària i que, per tant, 
ni es podria avaluar sobre un procés que s'hagués realitzat efectivament, ni es podria comprovar fins a quin punt hauria estat profitós en l'aprenentatge d'alumnes reals d'una escola real.

En resum, la nostra proposta de treball tenia l'inconvenient que era una simulació no aplicada i que, per tant, partia amb un desavantatge molt seriós. Malgrat aquest problema, ens va semblar que igualment podia ser de gran utilitat perquè els estudiants veiessin les possibilitats del treball per a projectes i fessin comparacions amb allò que havien observat a les escoles.

Així que va caldre recordar que, en els projectes, és essencial afavorir l'esperit crític, la capacitat de comprensió i de gestió de la informació. Ens sembla que els projectes tenen una gran potencialitat per treballar el que anomenem "qüestions socialment vives" o "problemes socials rellevants": es tracta que els problemes del present i l'educació per a la ciutadania democràtica adquireixin un rol fonamental a l'escola, de manera que els continguts disciplinars serveixin per conèixer i reflexionar sobre la realitat. ${ }^{2}$

També fou necessari remarcar que, en un projecte, tots els implicats hi han de tenir clara la finalitat de tot aquell esforç, què els motiva i per quina raó. Vam concloure que era recomanable que, en el títol del projecte, hi constés alguna pregunta que fes de fil conductor, per no perdre mai de vista la motivació fonamental.

Per tal d'establir uns paràmetres comuns als projectes que preparessin els nostres estudiants, els vam donar un model de formalització que haurien d'omplir en cada cas i que estava basat (amb algunes modificacions) amb els models per a unitats didàctiques que al seu dia va proposar el Departament d'Educació (Generalitat DE Catalunya, 2009). [Vegeu lrannex.]

Els vuit projectes que els nostres estudiants van preparar foren els següents:

2 Diverses aportacions sobre aquesta temàtica als materials de les VII Jornades Internacionals de Recerca en Didàctica de les Ciències Socials: "Les qüestions socialment vives i l’ensenyament de les ciències socials, la geografia i la història", Universitat Autònoma de Barcelona, 25-27 de febrer de 2010. [Data de consulta: 16-10-2011] <http://jornades.uab.cat/dcs/content/vii-jornades $>$.
El període d'eleccions. Com s'arriba a ser alcalde i a fer-ne?

Aquest projecte, centrat en el municipi de Mont-roig del Camp, pretenia que els alumnes entenguessin el funcionament de les eleccions municipals i les obligacions dels regidors i de l'alcalde.

Com és Vila-seca? Com ens agradaria que fos?

Tenia com a finalitat conèixer tot el terme municipal: les característiques geogràfiques i socials, i el patrimoni de què disposa. A partir d'aquest coneixement, proposava mesures per fer front als principals problemes de la localitat $\mathrm{i}$ millorar-ne els aspectes més deficients.

Port Aventura, una mostra real d'altres cultures?

A partir de la preparació d'una suposada visita a Port Aventura, presentava una anàlisi des d'un punt de vista crític d'algunes de les cultures que s'hi representen.

\section{S'està perdent l'agricultura?}

Situat en una escola de Vandellòs, proposava conèixer les característiques dels principals conreus del municipi i la seva evolució durant les últimes dècades, $\mathrm{i}$ es preguntava si eren viables econòmicament.

\section{Les llaminadures.}

A partir de l'interès per saber com i on es fan, i els mecanismes de distribució, es treballaven aspectes relacionats amb l'economia, la història, la salut i l’alimentació.

Tarragona, candidata als Jocs del Mediterrani 2017.

Aprofitava la candidatura presentada als Jocs (aleshores la ciutat encara no havia estat elegida) per conèixer tant els indrets de Tarragona on es realitzarien com els països que hi participarien $\mathrm{i}$ les proves esportives en què competirien.

\section{El delta de l'Ebre.}

Situat a l'escola de la Fatarella, el projecte volia que els alumnes investiguessin l'evolució del Delta, l'estat actual (extensió, clima, flora, fauna, demografia, economia i peculiaritats lingüístiques) 
i les possibles transformacions que pot patir en el futur.

\section{El delta de l'Ebre, avui.}

Des d'una escola de l'Aldea, s'incideix més amb les característiques orogràfiques actuals del Delta, els conreus, la vegetació i la fauna.

\section{Reflexions sobre els treballs "per projectes" pla- nificats pels alumnes}

Fer un balanç de tots aquests projectes és complex. En primer lloc, el model de formalització en una fitxa per al conjunt de cada projecte va provocar algunes disfuncions. Algunes vegades, va fer la sensació que alguns grups atorgaven més importància a redactar correctament la fitxa general que a assegurar-se que les activitats tinguessin un sentit i estiguessin formulades correctament, com si donessin més valor a la forma que al contingut, a omplir pàgines que a vigilar de no caure en errors, com ara usar vocabulari inadequat o plantejar activitats poc realistes $o$ desviades excessivament del fil central del projecte.

Certs projectes no van acabar de perfilar adequadament una pregunta que centrés l'atenció de totes les activitats, que marqués un objectiu i un punt d'interès ben definits. En alguns casos hi hagué massa divagació en les explicacions, temporitzacions irrealitzables o manca de precisió a l'hora de formular els objectius i els criteris d'avaluació. Alguns grups, en la seva proposta, van caure en l'error (massa habitual en els nostres estudiants) de no discernir allò que era fonamental d'allò que era accessori, o de mencionar a la fitxa objectius i criteris d'avaluació que després no apareixien en cap de les activitats d'ensenyament $\mathrm{i}$ aprenentatge programades.

De vegades, algunes d'aquestes activitats estaven explicades de forma poc meditada, amb problemes com ara:

- Accions que es proposen gairebé de manera rutinària; per exemple: debats (sense indicar sobre què), entrevistes (sense indicar ni a qui ni amb quina finalitat), preparació de dossiers (sense conèixer-ne l'objectiu) o sortides (sense un treball adequat previ ni una reflexió posterior ben travada).

- Errors greus en alguns continguts que s'havien d'abordar i que, per tant, havien de dominar els que proposaven el projecte.

- Desordre en els plantejaments; per exemple: un projecte proposava fer primer una entrevista a l'alcalde i després visitar l'Ajuntament per entendre'n l'organització i les tasques que s'hi realitzen.

- Graella d'avaluació molt extensa i repetitiva, que un mestre real, amb alumnes reals, sempre trobaria poc pràctica.

- Repetició de tòpics i estereotips habituals i que des de l'escola s'haurien d'evitar; per exemple: confondre conceptes com ara "cultures", "països" i "estats", com si fossin equivalents i intercanviables.

- Activitats inviables perquè eren excessives (com ara conèixer les normes de tots els esports dels Jocs del Mediterrani) o perquè era impossible trobar-ne la documentació necessària.

- Informacions extretes directament de llocs web o de llibres sense haver-les comprès bé ni haver-les contrastat.

Creiem que algunes de les principals deficiències dels projectes presentats pels nostres estudiants mostren un problema de formació de fons: tenim la sensació que molts dels estudiants donaven més importància a treballar les qüestions formals i els aspectes suposadament motivadors que a concretar les activitats d'ensenyament i aprenentatge i adequar-les als objectius plantejats, per tal de millorar la formació dels infants. Tanmateix, no tot va ser negatiu, ni de bon tros. Hi hagué propostes brillants, i els comentaris i debats posteriors, fets dins l'aula, van ser extremament útils perquè els nostres estudiants s'adonessin d'alguns punts febles i de com corregir-los.

En resum, aquesta activitat fou de gran profit i va permetre treballar particularment dos aspectes fonamentals en un mestre:

- La capacitat destructurar un projecte a partir d'un problema real, articular-lo de forma lògica i plantejar activitats a partir de qüestions de l'entorn social immediat. 
- La capacitat de proposar activitats d'ensenyament i aprenentatge viables, ben plantejades i amb uns objectius clars.

La reflexió a partir, en aquest cas, de la "planificació de l'acció" (no pas directament a partir de l'acció docent, com òbviament seria el més desitjable) també té una gran potencialitat, si es fa de manera realista i sincera, contrastant opinions i intentant arribar a conclusions, a partir de les consideracions sorgides des dels estudiants mateix. Un hàbit que ha de ser decisiu en el seu futur com a mestres.

Valorem, doncs, com a molt positiu, que, en el període de formació inicial, els futurs mestres tinguin l'oportunitat de planificar, estructurar i analitzar situacions que poden ser un projecte per a les aules de primària, i també que aprenguin a valorar de manera crítica totes les preteses "innovacions" que cíclicament van bombardejant el món escolar.

\section{Bibliografia}

Anguita, M.; Hernández, F., i Ventura, M. (2010). "Los proyectos: tejido de relaciones y saberes". Cuadernos de pedagogía, 400, p. 7780.

Aranda Hernando, A. M. (2003). Didáctica del conocimiento del medio social y cultural en educación infantil. Madrid: Síntesis.
Domínguez Garrido, M. C. (coord.) (2007). Didáctica de las ciencias sociales para primaria. Madrid: Pearson Educación.

Escamilla, A. (2008). Las competencias básicas: claves y propuestas para su desarrollo en los centros. Barcelona: Graó.

Gavaldà, A.; Girondo, L.; Macaya, A.; Pons, J. M., i Conde, C. (2010). "Competències i interdisciplinarietat". Comunicació Educativa, 23, p. 4-9.

Generalitat de Catalunya (2009). Del currículum a les programacions. Una oportunitat per a la reflexió pedagògica a l'educació bàsica. Barcelona: Generalitat de Catalunya.

Hernández, F., i Ventura, M. (1994). La organización del currículum por proyectos de trabajo: el conocimiento es un calidoscopio. Garcelona: Graó i ICE Universitat de Barcelona.

Kincheloe, J. (2001). Hacia una revisión crítica del pensamiento docente. Barcelona: Octaedro.

Martín García, X. (2006). Investigar y aprender. Cómo organizar un proyecto. Barcelona: ICE Universitat de Barcelona.

Pozo, J. (2010). "La transversalidad como enfoque didáctico: enseñar y aprender a través de conocimientos específicos". VALLÈs, J.; ÁlVAReZ, D., i Rickennmann, R. (ed.). L'activitat docent: intervenció, innovació, investigació. Girona: Universitat de Girona. 


\section{Model de formalització d'un projecte}

Taula núm. 1

\begin{tabular}{|c|c|c|c|c|}
\hline Grup classe & Durad & Període & Curs escolar & Professors \\
\hline \multicolumn{2}{|c|}{ Àrees } & \multicolumn{3}{|c|}{ Títol i justificació del projecte } \\
\hline \multirow{2}{*}{\multicolumn{2}{|c|}{ Objectius d'aprenentatge }} & $\begin{array}{l}\text { Competències bàsiques } \\
\text { (contribució a..) }\end{array}$ & Crite & ació \\
\hline & & & & \\
\hline \multicolumn{5}{|c|}{ Continguts } \\
\hline
\end{tabular}

Taula núm. 2

\begin{tabular}{|c|c|c|c|c|}
\hline \multicolumn{5}{|c|}{ ACTIVITATS D’ENSENYAMENT/ APRENENTATGE I AVALUACIÓ } \\
\hline $\begin{array}{c}\text { Sessió núm. } \\
\text { (hores) }\end{array}$ & $\begin{array}{c}\text { Objectius } \\
\text { de la sessió }\end{array}$ & $\begin{array}{c}\text { Activitats d’aprenentatge } \\
\text { (i org. social) }\end{array}$ & Recursos a utilitzar & $\begin{array}{c}\text { Avaluació } \\
\text { (activitats o observacions } \\
\text { a realitzar) }\end{array}$ \\
\hline & & & & \\
\hline & & & & \\
\hline & & & & \\
\hline & & & \\
\hline & & & Alumnes d'aprenentatge ràpid \\
\hline
\end{tabular}

